\title{
Treatment efficiency of a combination of alternative technologies in removing pollutants from pesticide containing wastewater
}

\author{
Toan Van Pham ${ }^{1^{\dagger}}$, Vinh Mai Phuoc ${ }^{1}$, Dung Van Nguyen ${ }^{2}$, Jiro Koyama ${ }^{3}$ \\ ${ }^{1}$ Department of Environmental Engineering, Cantho University, Cantho 941, Viet Nam \\ ${ }^{2}$ Department of Electrical Engineering, Cantho University, Cantho 941, Viet Nam \\ ${ }^{3}$ Faculty of Fisheries, Kagoshima University, Shimoarata Kagoshima, Japan
}

\begin{abstract}
Pesticide containing wastewater is concerned due to their toxicity to human health and the environment, and therefore, is attracted much attention by public communities and scientists. This type of wastewater can be treated by conventional treatment methods including physical, chemical, biological methods and so on. Unfortunately, the efficiency of these methods are mostly undesired as expectation because they cannot completely remove toxic organic pollutants from wastewater. In this study, an experiment on laboratory scale model of cold plasma technology, a well-known water treatment method in recent decades, was performed to assess its efficiency on removing pesticide fenobucarb from the wastewater. Furthermore, another experiment on laboratory scale model of the cold plasma combined with coagulation/flocculation and ion exchange process was implemented to assess the efficiency of these combination and each process as well on treatment of pesticide containing wastewater. Experimental results demonstrated that the model of technologies combined was high effective in removing organic pollutants from wastewater. However, the specific efficiency of cold plasma technology in treating wastewater was low. Treatment time, energy supply and wastewater characteristics are the factors which are necessary to be further studied for cold plasma technology application.
\end{abstract}

Keywords: Cold plasma, Coagulation, Flocculation, Ion exchange

\section{Introduction}

Environmental contamination of water by pesticide residues is originated not only from agricultural fields but also from agricultural chemical producing industries. In recent decades, pesticide use in agricultural production has been rapidly increased all over the world and in the Vietnamese Mekong Delta particularly [1]. Increasing use of agrochemicals has led to a rapid development of the pesticide producing companies on over the world [2]. In Viet Nam, according to inventory data from the Plant Protection Department, there were approximately 100 pesticide producing factories with the production capacity from 30,000 to 40,000 tons/year, including more than 1,700 active ingredients and 4,080 trade products in the whole country in 2018 [3]. Environmental protection efforts in pesticide production and pollution control in regard to toxic pesticides are really concerned to public health. Therefore, pesticide containing wastewater has to be strictly treated before discharged into the environment.
Wastewater originated from pesticide production is a mixture of inorganic and organic components, and is characterized by various physic-chemical properties depending on type of pesticides produced. A study of Chavan et al. [4] revealed that the presence of sulfur and oil/greases in pesticide containing wastewater were at high concentrations, especially with the occurrence of organochlorine pesticides - a toxic substance to aquatic animals. Therefore, if there is no suitable managing mechanisms of such pesticide wastewaters, they could directly affect to health of workers in pesticide producing factory, surrounding communities and the environment.

Recently, various treatment processes have been investigated to remove pesticides from water. The conventional and advanced processes include hydrolysis, oxidation, adsorption, photo-catalysis, ultrasonic irradiation, ionizing radiation [5-8]. However, these treatment processes still have limitations due to the formation of unwanted by-products and the partial destruction of target pesticides. Therefore, finding novel treatment protocols is an urgent
This is an Open Access article distributed under the terms of the Creative Commons Attribution Non-Commercial License (http://creativecommons.org/licenses/by-nc/3.0/) which permits unrestricted non-commercial use, distribution, and reproduction in any medium, provided the original work is properly cited.

Copyright (C) 2021 Korean Society of Environmental Engineers
Received May 23, 2020 Accepted November 18, 2020

${ }^{\dagger}$ Corresponding author

Email: pvtoan@ctu.edu.vn

Tel: +84949775658

ORCID: 0000-0001-2254-5294 
need to completely remove pesticide residues from water.

In the last decades, plasma technology has been considerably attracted by scientists in various environmental applications [9]. The cold (non-thermal) plasma technology can degrade and detoxify pesticides in wastewater and produce no secondary pollutants during the treatment process [10]. The cold plasma is also a well-known method of cleaning water due to the production of ultraviolet radiation, shock waves and highly reactive species that oxidize and mineralize the pollutants into $\mathrm{CO}_{2}, \mathrm{H}_{2} \mathrm{O}$ and simpler inorganics. The cold plasma can be obtained by various electrical discharges such as corona discharge, atmospheric pressure plasma jet, micro hollow cathode discharge, dielectric barrier discharge and etc. Among types of electrical discharges of cold plasma, dielectric barrier discharge is proposed in many researches due to its high yield of reactive species which improves the rate of pollutant decomposition [11]. In this study, experiments on a dielectric barrier discharge plasma reactor used coaxial cylindrical electrodes was performed. Cold plasma was demonstrated a great efficiency in disinfecting micro-organisms, degrading high molecular weight organic compounds into simple matters at high voltage of electricity, reducing the content of chemical oxygen demand in wastewater, and removing color of water [10-12]. Additionally, cold plasma could also degrade the residue of antibiotic sulfadiazine (spiked at concentration of $10 \mathrm{mg} / \mathrm{L}$ ) used in livestock feeding [13], decompose pesticide quinalphos in the aqueous solution with the efficiency of $98.2 \%$ at power capacity $120 \mathrm{~W}$ and $90 \mathrm{~min}$ of treatment time [14]. However, some recent studies revealed that the treatment efficiency of cold plasma is much affected by the electrical voltage, treatment time and gas flow $[14,15]$. Also, this technology can create unpredicted impacts such as increase of electrical conductivity, reduction of $\mathrm{pH}$ and formation of nitrogen compounds in water after treatment [16]. The majority of previous studies often only assessed the wastewater treatment efficiency of the cold plasma technology alone $[17,18]$. It is lack of data on the treatment efficiency of the combination of the cold plasma with other treatment methods in wastewater treatment. Therefore, the main objective of this study was to assess the treatment efficiency of pesticide wastewater by a combination of cold plasma with coagulation/flocculation and ion exchange processes. Coagulation and flocculation method is well known as a pretreatment stage which enhances the efficiency of subsequent processes including sedimentation and filtration in a water treatment system. Coagulant plays a main role in destabilizing colloidal particles in the coagulation process. This is followed by the flocculation process in which the unstable particle size of solution is increased into larger flocs. By this mechanism, the colloidal particles and suspended solids are able to be effectively removed from the solution. Coagulation and flocculation process has highly effective for removing organic pollutants with high concentration [19]. Coagulation and flocculation process can efficiently remove the persistent organic pollutants and reduce the content of heavy metals in wastewater [20, 21]. Ion exchange was found as a strong potential alternative for removing organic matters from water. Application of ion exchange resins for pollutants in water is affected by the characteristic of the resins, the water quality and the properties of the pollutants. Ion exchange process was used to remove dissolved substances, natural organic matters and heavy metals in water/wastewater [22-24]. Ion exchange resin was also found highly adsorptive for eliminating perfluorooctane sulfonate in water at low concentration [25].

The aim of this work was to investigate the production of pesticides and its wastewater property at the target pesticide factory in the first stage. In the second stage, the removal efficiency of a target pesticide was performed on a laboratory scale model of dielectric barrier discharge cold plasma reactor used coaxial cylindrical electrodes. Then an experiment on combination of the dielectric barrier discharge cold plasma with coagulation/flocculation and ion exchange process was conducted to assess the treatment efficiency of pesticide containing wastewater.

\section{Materials and Methods}

\subsection{Data Collection on Pesticide Production}

Information on the type of pesticides produced in the study year 2018 and the situation of wastewater treatment at a pesticide factory was obtained from secondary data. The secondary data is inventory documents of pesticide producing activities and environmental reports of the factory.

\subsection{Experimental Methods}

\subsubsection{Experiment 1: Treatment efficiency of active ingredient feno- bucarb by cold plasma technology}

Batch experiments were performed with pesticide fenobucarb containing wastewater collected from a storage tank of raw wastewater at the pesticide factory. A laboratory scale model of cold plasma with coaxial electrode cylinder reactor modified from Kuraica's research (Fig. 1) [17]. Operation parameters of the model include water flow of $0.7 \mathrm{~L} / \mathrm{min}$ for a plasma chamber, water film thickness inside plasma chamber of approximately $1 \mathrm{~mm}$, electrical voltage of $17 \mathrm{kV}$, and a frequency of $50 \mathrm{~Hz}$. A total of $17 \mathrm{~L}$ of raw wastewater from influent tank (a) was passed through each cold plasma chamber (b)

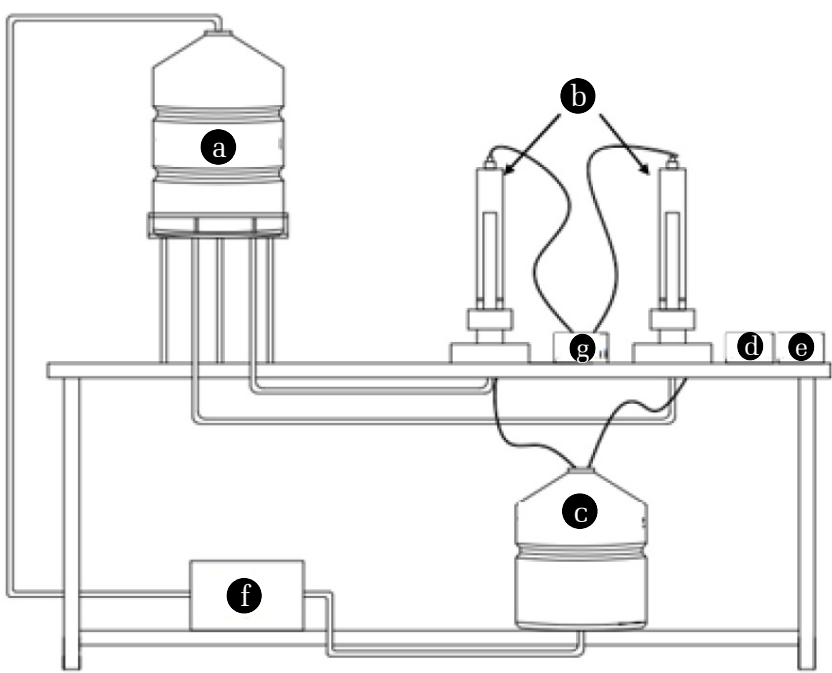

Fig. 1. Schematic sketch of lab scale model with cold plasma reactor: (a) influent and (c) effluent tank; (b) plasma chamber; (d) high voltage source; (e) resistive divider; (f) water pump; (g) air pump. 
at a certain water flow as a film inside the chamber. Due to appearance of discharges generated by high voltage source (d) inside the column chamber, plasma was formed in liquid or the gas-liquid interface. Oxidizing species were generated by plasma such as radicals ( ${ }^{*} \mathrm{OH},{ }^{*} \mathrm{O},{ }^{*} \mathrm{H}$ ), ozone, ultraviolet (UV) light. An air pump (g) was used to supply air to the plasma chamber to enhance ozone concentration. Wastewater was circulated between the influent tank (a) and effluent tank (c) by water pump (f) for $6 \mathrm{~h}$. The experiment was performed with three times of replication.

\subsubsection{Experiment 2: Treatment efficiency of pesticide containing wastewater via a combination of three methods}

Based on the results of experiment 1, an experimental process on assessing the treatment efficiency of pesticide containing wastewater of laboratory scale model of a system with the combination of three processes: (a) coagulation/flocculation, (b) cold plasma, and (c) ion exchange was developed as illustrated in Fig. 2. Raw wastewater was collected from the storage tank of the pesticide factory. Before treatment with the coagulation/flocculation process, oil/greases and other floating matters in wastewater were removed through the flotation process by the ceramic air distributor located at the tank bottom. At the coagulation/flocculation process, wastewater was firstly added the coagulant poly aluminum chloride (PAC) 31\% with a dosage of $2500 \mathrm{mg} / \mathrm{L}$ and then polymer anion with concen- tration of $4 \mathrm{mg} / \mathrm{L}$ as a flocculent. After that $\mathrm{pH}$ of the solution was adjusted to 10 so as to enhance the degradation of persistent organic substances in wastewater and left for sedimentation for $30 \mathrm{~min}[13,26]$. Wastewater after sedimentation was passed through the cold plasma process by a water pump with water flow rate of $2 \mathrm{~L} / \mathrm{min}$. Electrical voltage of power source generated plasma was $18 \mathrm{kV}$. Finally, water was pumped into a reactor of ion exchanger to remove ions generated in wastewater before discharging to the environment. Ion exchange reactor was structured by poly vinyl chloride plastic tube with inner diameter of $60 \mathrm{~mm}$ and equipped with anion exchange resin GS3000 with volume of $1.6 \mathrm{~L}$.

\subsection{Chemicals}

Coagulant poly aluminum chloride (PAC) 31\% was purchased from Fengbai Industrial Company, China. Anion exchange resin GS3000 was produced by Indion manufacturer. Sodium hydroxide $(\mathrm{NaOH})$ 99\% from Merck was used to adjust the $\mathrm{pH}$ value of wastewater. All standards and reagents used in the pesticide analysis were all analytical grade as reported in Table 1 .

\subsection{Analysis}

2.4.1. Analysis methods of water physicochemical parameters

Physicochemical parameters of water quality were determined

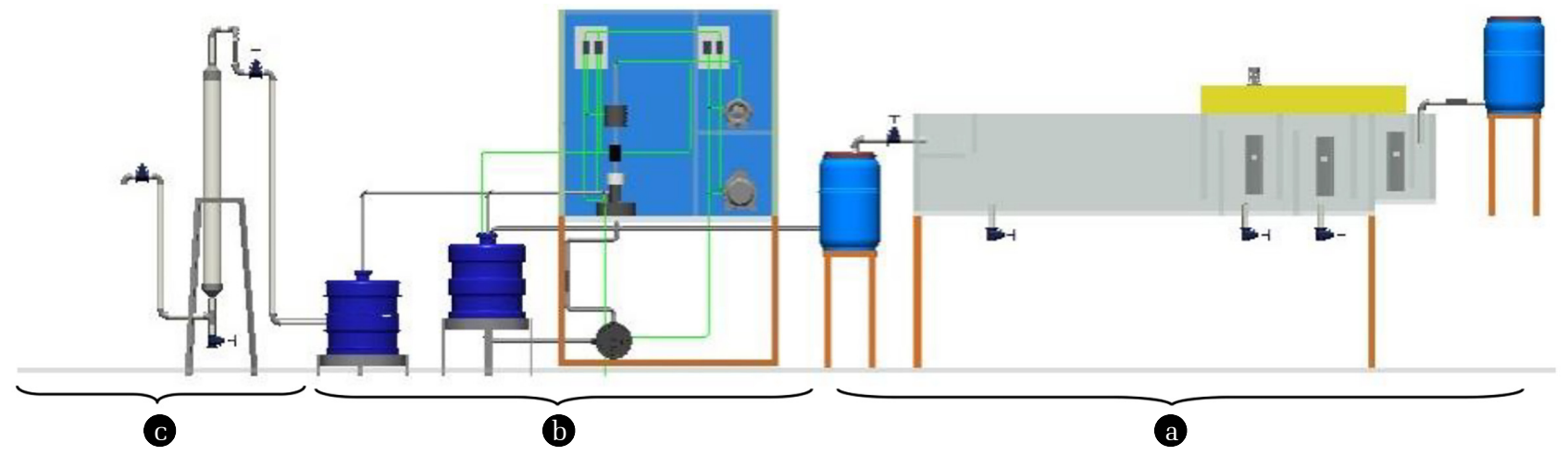

Fig. 2. Schematic of lab scale model of pesticide containing wastewater treatment system: (a) coagulation/flocculation process; (b) cold plasma process; and (c) ion exchange process.

Table 1. Standards and Reagents Used for Pesticide Analysis

\begin{tabular}{lcc}
\hline Standards/Reagents & Manufactures & Purity (\%) \\
\hline Chlorpyrifos & Riedel - de Haen (Seelze, Germany) & 98.6 \\
Diazinon & Riedel - de Haen (Seelze, Germany) & 98.6 \\
Fenobucarb & Riedel - de Haen (Seelze, Germany) & 98.6 \\
$\delta-$ HCH & Institute of Industrial Organic Chemistry (Warsaw, Poland) & $\geq 99$ \\
Fluorene-D10 & Cambridge Isotope Laboratories (Andover, USA) & 98 \\
n-Hexane & J.T.Baker analyzed HPLC & 99.5 \\
Ethyl-acetate & J.T.Baker analyzed HPLC & 99.6 \\
Toluene & J.T.Baker analyzed HPLC & 99.7 \\
Acetone & J.T.Baker analyzed HPLC & 99.3 \\
Methanol & J.T.Baker analyzed HPLC & 99.9 \\
\hline
\end{tabular}


with methods presented in the standard methods for the examination of water and wastewater [27]. The concentrations of ozone in water was measured by the instrument Hanna HI38054 ozone test kit.

\subsubsection{Extraction method and analysis procedure of target pesti- cides}

Three target active ingredients including chlorpyrifos, diazinon and fenobucarb in wastewater were extracted and analyzed according to a method in the study of Toan et al. [1], modified as the following.

\subsubsection{Method of sample extraction}

Water samples were passed through the fiber-glass filters with a pore size of $8 \mathrm{~mm}$ (Millipore AP 25) and $0.45 \mathrm{~mm}$ (Millipore AP 15) to remove suspended matters. In the next step, the samples were solid-phase extracted with Strata C18-E cartridges. The cartridges were preconditioned by sequentially eluting $3 \mathrm{~mL}$ n-hexane, $3 \mathrm{~mL}$ ethyl acetate, $1 \mathrm{~mL}$ methanol and $1 \mathrm{~mL}$ water HPLC. The samples $(500 \mathrm{~mL})$ were then passed through the conditioned cartridges by tubing adaptors with a vacuum flow rate of $2-4 \mathrm{~mL} / \mathrm{min}$. Afterwards the cartridges were washed with $2 \mathrm{~mL}$ HPLC water. In order to dry the C18 sorbent material, nitrogen gas was passed through it for $30 \mathrm{~min}$. Analytes were eluted from the cartridges by $6 \mathrm{~mL}$ ethyl acetate and then $6 \mathrm{~mL}$-hexane. The evaporation process at laboratory condition was applied to concentrate the eluted solution. This process was performed by flowing nitrogen gas after adding $300 \mu \mathrm{L}$ of toluene into the eluted solution as a keeper. Internal standard flourene-D10 of $1 \mathrm{mg}$ (50 mL flourene - D10 in acetonitrile $20 \mathrm{mg} / \mathrm{mL}$ ) was added. The analytes concentrated in acetonitrile were transferred to a vial, filled up to $1 \mathrm{~mL}$ and stored at $-20^{\circ} \mathrm{C}$ until analysis.

\subsubsection{Analysis procedure}

The target pesticides (i.e. chlorpyrifos, diazinon and fenobucarb) were quantified by a Shimadzu GC - 2010 gas chromatograph which was linked to Shimadzu GCMS - QP2010 mass selective detector and equipped with a Shimadzu AOC - 20S automatic sampler. The GC was fitted with a Rxi@5Sil MS W/Inter fused silica capillary column: $30 \mathrm{~m}$ length x $0.25 \mathrm{~mm} \mathrm{ID} \times 0.5 \mu \mathrm{m}$ film thickness. Helium was used as the carrier gas with a constant flow rate of $1.0 \mathrm{~mL} / \mathrm{min}$. The following temperature program was employed during analysis: (1) an $80^{\circ} \mathrm{C}$ initial temperature within a duration of $2 \mathrm{~min}$; (2) an increase at $15^{\circ} \mathrm{C} / \mathrm{min}$ to $180^{\circ} \mathrm{C}$; (3) another increase at $10^{\circ} \mathrm{C} / \mathrm{min}$ to $250^{\circ} \mathrm{C}$, held for $2 \mathrm{~min}$; (4) then another ramp up $10^{\circ} \mathrm{C} / \mathrm{min}$ to $300^{\circ} \mathrm{C}$, held for $5 \mathrm{~min}$. The injector block temperature was held at $250^{\circ} \mathrm{C}$. The injection volume was $1 \mu \mathrm{L}$ for all samples as well as for the standards. Pesticide compounds were determined according to the selected ion monitoring mode.

\subsection{Data Analysis}

Data obtained from the inventory documents of pesticide producing activities and environmental reports of the factory was statistically described by the program Microsoft Excel version 2013. Results of the experiments were used to assess the efficiency of wastewater treatment in terms of the physicochemical parameters and the concentration of target pesticides in water at each process of the models. The treated water quality was compared with the allowance value of the national technical regulation on industrial wastewater quality (QCVN 40:2011/BTNMT) promulgated by the Ministry of Natural Resources and Environment, Viet Nam [28].

\section{Results and Discussion}

\subsection{General Information on the Pesticide Producing Factory}

\subsubsection{Types of pesticides produced at the factory}

Agrochemicals produced from the factory were included many types of products such as insecticides, fungicides, herbicides, molluscicides and rodenticides. According to the inventory documents of the factory, 24 products were manufactured at the period of investigation (Table S1). They were classified into various categories, consisting of emulsifiable concentrate (EC), soluble concentrate (SC), wettable powder (WP), soluble liquid (SL), granules (GR), depending on the proportion of the main chemical mixtures and subcomponents. These formulations aim to improve the property of pesticides for handling, storage, application and safety in use. According to survey results of the authors, pesticide containing wastewater of the factory mostly originated from the production lines of EC, SC, WP and SL pesticide products. Wastewater was often generated from the cleaning process at the end of each producing shift.

\subsubsection{Properties of wastewater and target pesticides}

Raw pesticide containing wastewater used in this study was collected at the storing tank of the factory. The wastewater properties of sampling in three continuous days were presented at Table S2. It could be seen that the raw wastewater was characterized with slight acidity. The $\mathrm{pH}$ value ranged from 5.8 to 6.3 and water temperature slightly fluctuated from 28.2 to $30.5^{\circ} \mathrm{C}$. Electrical conductivity of wastewater was rather high, ranged from 334 to 394 $\mu \mathrm{S} / \mathrm{cm}$. It might be much dissolved particles in the wastewater. Concentration of suspended solid ranged from 24.3 to $38 \mathrm{mg} / \mathrm{L}$. The content of organic substances in the wastewater could be high because the chemical oxygen demand ranged from 522 to 775 $\mathrm{mg} / \mathrm{L}$. Average concentration of nitrite was higher than that of nitrate in the wastewater. It seemed that the wastewater was being on the process of degradation. Therefore the content of dissolved oxygen was extremely low, ranged from 0.6 to $0.8 \mathrm{mg} / \mathrm{L}$. The physicochemical properties of the wastewater was unstable during three sampling days. Moreover, the authors found that the property of the wastewater was influenced by the production activity (i.e. production frequency and type of pesticides) in the factory.

In this study, three active ingredients from the list of agrochemicals were selected as the target pesticides based on their physicochemical properties, toxicity and production frequency at the factory. Of which two pesticides were organophosphorus compounds, including chlorpyrifos and diazinon. They were the main active ingredients of two trade products of the factory, namely Careman and Cazinon, respectively. According to the toxicity classification of WHO, chlorpyrifos is a slightly hazard substance to human health, but it is extremely toxic to aquatic animals, especially to fish [30]. Chlorpyrifos is a broad spectrum chlorinated organophosphate insecticide. Its solubility in water is $1.4 \mathrm{mg} / \mathrm{L}$ (at $25^{\circ} \mathrm{C}$ ) 
and its soil sorption coefficient ranges from 360 to 31,000 depending on environmental conditions. Therefore chlorpyrifos does not partition easily from soil to water and often absorbed into particles in the water environment. Diazinon is classified into the group of category II (i.e. moderately hazardous), also harmful to aquatic organisms and the ecosystem [31]. Diazinon is a synthetic organophosphate pesticide. Its technical grade is an amber to brown liquid. Solubility of diazinon in water is low and depends on water temperature. For example its solubility in water at $20^{\circ} \mathrm{C}$ is $40 \mathrm{mg} / \mathrm{L}$ [32]. Soil sorption coefficient of diazinon ranges from 40 to 854 . When released into the environment, diazinon is moderately persistent and moderately mobile. Besides, an active ingredient of carbamate group, fenobucarb, was selected as the remaining target pesticide. Fenobucarb is an insecticide belonging to class of moderately hazardous substances according to WHO's recommended classification. Fenobucarb's solubility in water is $420 \mathrm{mg} / \mathrm{L}$ at $20^{\circ} \mathrm{C}$. This compound is less absorbed into particles, with soil sorption coefficient of 1068. This active ingredient is the main component of a trade pesticide product of the factory, namely Palm. These target pesticides were demonstrated that they are more susceptible to alkaline hydrolysis and highly degradable in the neutral to basic conditions [33, 34]. They are able to accumulate as existing in natural environment, harm to aquatic organisms and ecosystems or cause negative effects to the environment [35-37].

\subsection{Treatment Efficiency of Pesticide Containing Wastewater via Cold Plasma Technology (Experiment 1)}

This lab scale experiment was performed at given conditions of cold plasma reactor to assess the removal efficiency of pesticide from wastewater. In this experiment, the cold plasma method was only tested its efficiency in removing fenobucarb from wastewater. The basic physicochemical parameters and concentration of fenobucarb in influent and effluent wastewater of the cold plasma reactor were determined through three replications on the experiment. Results of the experiments showed that the average $\mathrm{pH}$ value of influent was $6.04 \pm 0.14$, then rapidly dropped to $3.45 \pm 0.26$ of effluent. Decreasing of $\mathrm{pH}$ value could be caused by the oxidation mechanism of pollutants in wastewater. The oxidation process formed by cold plasma could create nitrogen compounds such as $\mathrm{NO}_{2}, \mathrm{HNO}_{2}$ and $\mathrm{HNO}_{3}[11,38]$. Average electrical conductivity of influent and effluent water was $639.33 \pm 6.66 \mu \mathrm{S} / \mathrm{cm}$ and 793 $\pm 34.39 \mu \mathrm{S} / \mathrm{cm}$, respectively. Increasing of electrical conductivity could be impacted by ozone, ultraviolet light and other oxidants which formed in the plasma reactor during treatment time. These strong oxidant agents could degrade organic and inorganic substances, and create ions or other particles in water which lead to increase of electrical conductivity. Turbidity of effluent was higher than that of influent. Increasing of turbidity could be the occurrence of particles which were created by the oxidation processes of pollutants in wastewater. When the treatment time was longer, these particles were created much more as without any their removal mechanism from water in this experiment. Chemical oxygen demand (COD) parameter indicates the presence of organic substances in wastewater. Average influent COD concentration was $772.33 \pm 37.61 \mathrm{mg} / \mathrm{L}$. After treatment with the cold plasma, effluent COD concentration decreased to $717 \pm 26.89 \mathrm{mg} / \mathrm{L}$. It could be seen that treatment efficiency of cold plasma for organic

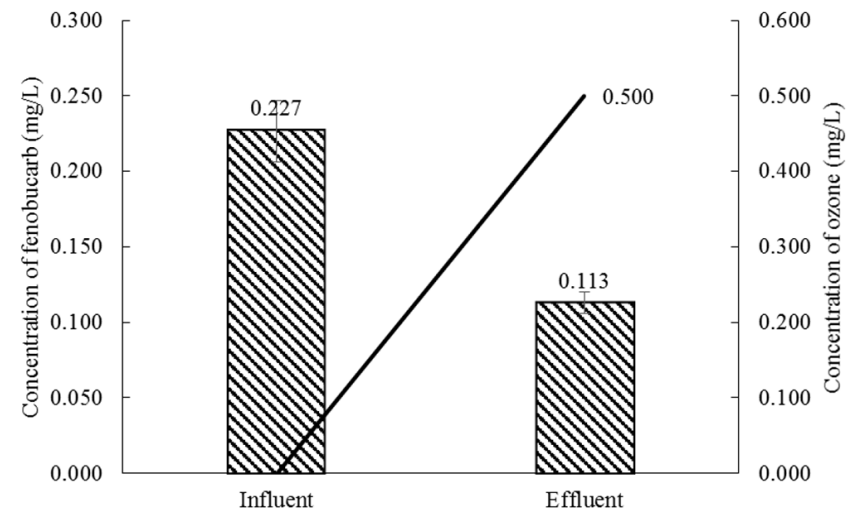

๙రJFenobucarb (mg/L) - Ozone (mg/L)

Fig. 3. Concentration of fenobucarb and ozone in the influent and effluent.

substances was low in this study. The low COD treatment efficiency could be the following reasons: (1) there was not any pretreatment process for influent so as to reduce background organic matters in water which could prevent the ultraviolet light in plasma chamber [39]; (2) strong oxidant agents formed from plasma was not much enough to completely degrade the high molecular weight organic compounds in pesticide containing wastewater. However, decreasing of effluent COD concentration indicated that degradation of organic substance happened partly, especially with pesticide compounds in wastewater. As shown in Fig. 3, pesticide fenobucarb concentration of influent was $0.227 \pm 0.020 \mathrm{mg} / \mathrm{L}$. After treatment with the cold plasma effluent fenobucarb was detected with an average concentration of $0.113 \pm 0.007 \mathrm{mg} / \mathrm{L}$, corresponding to the measured ozone concentration of $0.50 \mathrm{mg} / \mathrm{L}$. The removal efficiency of fenobucarb from the wastewater via the lab scale model of the cold plasma was $50.24 \%$. Several previous studies found that under the integrated impact of oxidant agents formed by the cold plasma such as free radicals, ultraviolet light, ozone and excited atoms, agro-chemicals could be degraded into intermediate fragments or ultimate simple products (e.g. $\mathrm{CO}_{2}$ and $\mathrm{H}_{2} \mathrm{O}$ ) [13-15].

\subsection{Treatment Efficiency of the Combination of Coagulation/ Flocculation, Cold Plasma and lon Exchange Processes (Experiment 2)}

\subsubsection{Physicochemical water quality parameters}

Pesticide wastewater used for this experiment was also collected at the wastewater storing tank of the factory, but wastewater quality was quite different compared to that of the experiment 1 because the water collection for two experiments was conducted at the different periods. Wastewater treatment efficiency of a lab scale model system for the combination of coagulation/flocculation, cold plasma and ion exchange processes was assessed through several of the physicochemical water quality parameters as presented in Table S3. The water $\mathrm{pH}$ value was much fluctuated between the processes of the treatment system. The input wastewater was characterized by slight acidity with average value $\mathrm{pH}$ of $6.36 \pm 0.10$. The water $\mathrm{pH}$ value of $9.70 \pm 0.04$ was determined after the coagulation/flocculation process when alkaline condition was adjusted so as to improve the degradation of persistent organic substances 
in wastewater [26, 34]. After passing the cold plasma process $\mathrm{pH}$ of water slowly dropped at $9.57 \pm 0.05$. It could been seen that nitrogen containing gases supplied to plasma reactor was dissociated into nitrogen radicals and then formed new products like $\mathrm{NO}_{2}$, $\mathrm{HNO}_{2}$ and $\mathrm{HNO}_{3}[11,38]$, leading to reduction of $\mathrm{pH}$. When wastewater was passed through ion exchange column, the process of ion exchange happened between ion $\mathrm{OH}^{-}$of water molecules and ion $\mathrm{Cl}^{-}$of the resin, leading a quick reduction of $\mathrm{pH}$ [40]. After ion exchange process, water $\mathrm{pH}$ of $7.71 \pm 0.24$ was determined. Such $\mathrm{pH}$ value met the allowance threshold of industrial wastewater quality, QCVN 40:2011/BTNMT [28].

Electrical conductivity of wastewater increased at all treatment processes of the system. Water EC value of the input $(361 \pm 20$ $\mu \mathrm{S} / \mathrm{cm})$ grew up to $618 \pm 53 \mu \mathrm{S} / \mathrm{cm}$ after coagulation/flocculation process. A part of this increasing was effected by ions generated from coagulation/flocculation process, another by ions created from sodium hydroxide solution for enhancing water $\mathrm{pH}$. Value of water EC was not much change after passing plasma process. However, after passing ion exchange column, value of EC increased to 789 $\pm 83 \mu \mathrm{S} / \mathrm{cm}$. Release of ion $\mathrm{Cl}^{-}$from the resin in ion exchange process could be the main impact of the increase of EC value.

In wastewater input of the model, the content of organic compounds was high, with average chemical oxygen demand concentration of $510 \pm 59 \mathrm{mg} / \mathrm{L}$. After coagulation/flocculation process, the COD value was fell to $285 \pm 68 \mathrm{mg} / \mathrm{L}$. Organic compounds existing in the raw wastewater may be included suspended solid particles, colloidal and dissolved matters. Coagulation/flocculation is a well-known method to remove suspended solids from agrochemical wastewaters [21]. Therefore, when the content of suspended solids in wastewater is reduced, COD concentration of wastewater decreases accordingly. After cold plasma process, COD concentration of wastewater was decreased to $239 \pm 36 \mathrm{mg} / \mathrm{L}$, as demonstrated in Fig. 4. As mentioned in the earlier section, cold plasma can create oxidants (e.g. ozone, $\mathrm{H}_{2} \mathrm{O}_{2}$ ), active species (i.e. ${ }^{*} \mathrm{OH},{ }^{*} \mathrm{O},{ }^{*} \mathrm{H},{ }^{*} \mathrm{O}_{2-,}{ }^{*} \mathrm{HO}_{2}$ ) and ultraviolet light [14, 41]. Due to the impact of these agents, the high molecular weight organic compounds are decomposed into intermediate compounds or simple products. However, COD treatment efficiency of this process

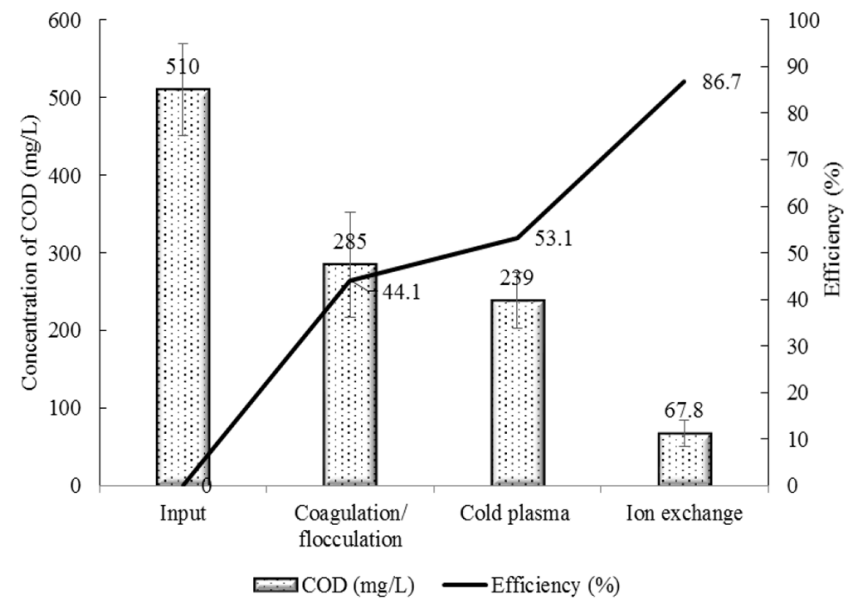

Fig. 4. Removal efficiency of COD from wastewater at the treatment processes. was rather low with $16.1 \%$ approximately. It could be explained that amount of oxidant agents formed was low in this process due to short retention time of water in this experiment. After ion exchange process, there was a rapid decreasing of COD concentration, from $239 \pm 36 \mathrm{mg} / \mathrm{L}$ to $67.8 \pm 16.8 \mathrm{mg} / \mathrm{L}$, corresponding to the treatment efficiency of $71.6 \%$. Ion exchange resin is well known to remove organic matters from water [40]. Organic compounds in wastewater could be absorbed via anion exchange resin $\mathrm{GS} 3000$, of which surface ion $\mathrm{Cl}^{-}$is replaced by the organic ions.

\subsubsection{Treatment efficiency for the target pesticides}

Analysis results of the wastewater treatment model indicated that, the content of fenobucarb was less changed when wastewater was passed through coagulation/flocculation and cold plasma processes. As illustrated in Fig. 5, its initial concentration was $3.381 \pm 0.224$ $\mathrm{mg} / \mathrm{L}$, then decreased to $3.285 \pm 0.552 \mathrm{mg} / \mathrm{L}$ and $3.213 \pm 0.204$ $\mathrm{mg} / \mathrm{L}$, respectively. The removal efficiency of fenobucarb from wastewater via two treatment processes was about $5 \%$ in total. It could be seen that the fenobucarb concentration of the input in this experiment was very high than that in the experiment 1. The reason of this difference is because the conduction period for the experiment 2 was at the same time with the production period of the fenobucarb containing trade product at the factory. Regarding physicochemical property, fenobucarb is relatively solute in water and less absorbed into particles [32]. Therefore its removal efficiency from water was low by the coagulation/flocculation process. In addition, as mentioned in the early section, because treatment time of the cold plasma stage in the experiment 2 was shorter than that in the experiment 1 , oxidant agents formed in the plasma reactor was not enough to effectively destroy fenobucarb in wastewater. Interestingly, after ion exchange process, there was a sharply reduction of fenobucarb concentration, from $3.213 \pm$ $0.204 \mathrm{mg} / \mathrm{L}$ to $0.811 \pm 0.722 \mathrm{mg} / \mathrm{L}$. Totally, the removal efficiency of fenobucarb from wastewater via the combination of three processes of the treatment model was $76 \%$.

As shown in Fig. 6, the degradation efficiency of pesticide diazinon after treatment with the coagulation/flocculation and plasma processes was $16 \%$. It could be seen that the removal efficiency of diazinon by the cold plasma process was very low. Such finding may be that treatment time of wastewater in cold plasma reactor

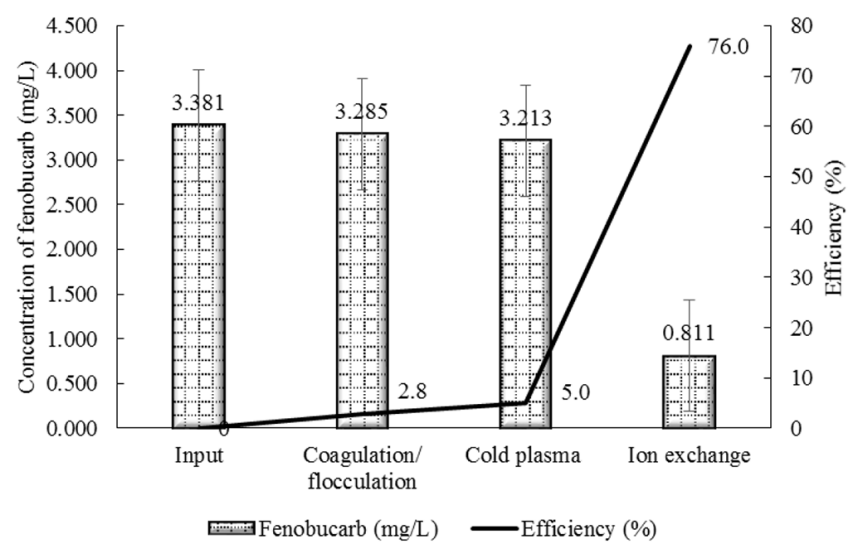

Fig. 5. Removal efficiency of fenobucarb from wastewater at the treatment processes. 
was not long enough to decompose diazinon. Concentration of diazinon decreased from $1.376 \pm 0.063 \mathrm{mg} / \mathrm{L}$ to $0.901 \pm 0.467$ $\mathrm{mg} / \mathrm{L}$ after passing through ion exchange process, corresponding with the efficiency of $34.5 \%$.

Total removal efficiency of pesticide chlorpyrifos via the combination of three treatment processes was $95.3 \%$. After treatment with the coagulation/flocculation process, chlorpyrifos was decreased more than a haft of initial concentration, from $1.887 \pm$ $0.524 \mathrm{mg} / \mathrm{L}$ to $0.581 \pm 0.157 \mathrm{mg} / \mathrm{L}$, corresponding to $69.2 \%$ in efficiency, as demonstrated in Fig. 7. Then, chlorpyrifos concentration also decreased from $0.525 \pm 0.197 \mathrm{mg} / \mathrm{L}$ to $0.088 \pm 0.039$ $\mathrm{mg} / \mathrm{L}$ when wastewater flowed through the ion exchange column.

Results of the experiment on the combination of three wastewater treatment processes revealed that the coagulation/flocculation process was the best effective in removal for chlorpyrifos (69.2\%), then for diazinon (15.5\%) and fenobucarb (2.8\%), respectively. After passing through the coagulation/flocculation process, the concentration of target pesticides was decreased because they adhered in particles and were removed by sedimentation. Removal efficiency of three pesticides in this process could be dependent upon their water solubility in order: fenobucarb $>$ diazinon $>$ chlorpyrifos. In addition, they might be degraded in alkaline condition of solution when $\mathrm{pH}$ value was enhanced to 10 . According to literature elsewhere [34], organophosphate pesticides are more susceptible and

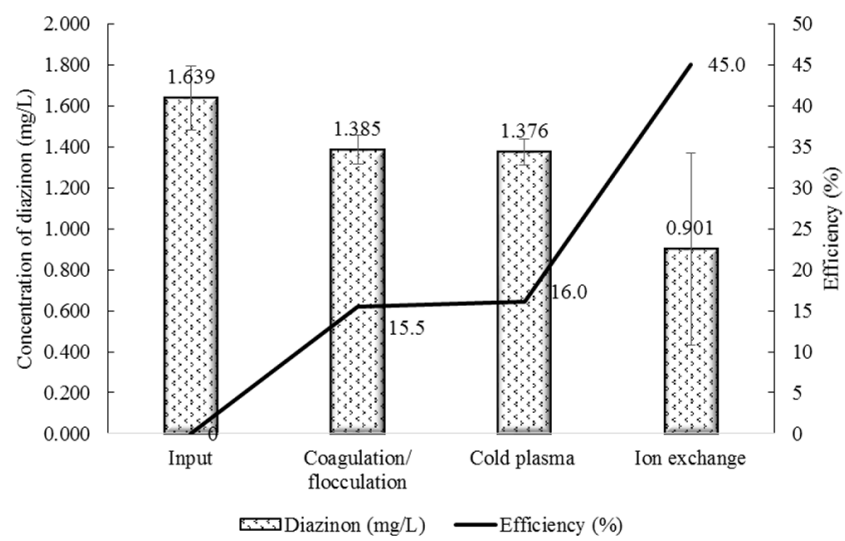

Fig. 6. Removal efficiency of diazinon from wastewater at the treatment processes.

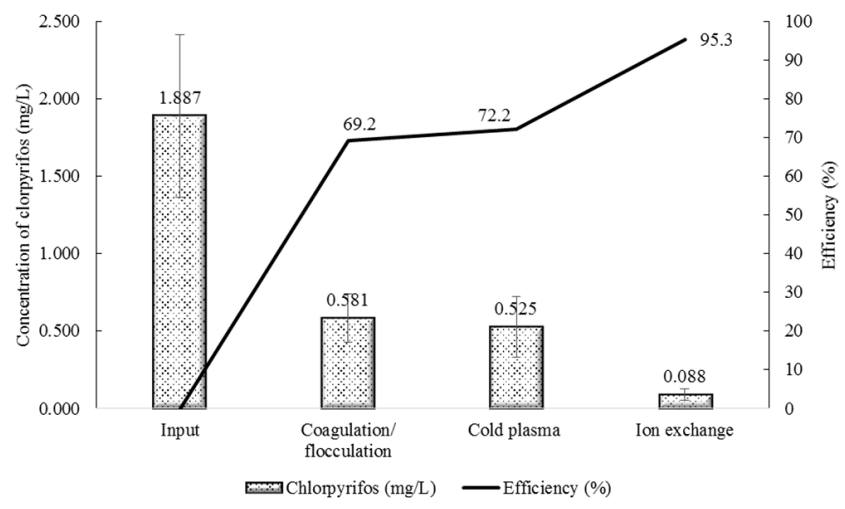

Fig. 7. Removal efficiency of chlorpyrifos from wastewater at the treatment processes. decomposable in alkaline condition. When water $\mathrm{pH}$ is higher than 7 in which some pesticides undergo degradation or chemical breakdown, a mechanism known as hydrolysis.

Removal efficiency of the cold plasma process was the lowest, ranging from $2-4 \%$. In treatment process via the cold plasma, pesticide compounds are degraded by strong oxidant agents formed from oxidation reactions in plasma zone. Several oxidants (e.g. ozone, hydroxyl radicals, and ultraviolet light) can breakout bonds of the molecular structure of pesticides and create intermediates, simple products like $\mathrm{CO}_{2}$ and $\mathrm{H}_{2} \mathrm{O}$ as the follow reactions [42]. However, oxidant agents were less created due to short treatment time in cold plasma process in this experiment. This could be a main reason leading to less treatment efficiency of pesticides in this study.

$$
\begin{gathered}
\mathrm{O}_{3}+\text { Pesticides } \underset{\mathrm{H}_{2} \mathrm{O}}{\stackrel{\text { UVlight }}{\longrightarrow}} \mathrm{CO}_{2}+\mathrm{H}_{2} \mathrm{O}+\text { Simple species } \\
* \mathrm{OH}+\mathrm{RH} \stackrel{\text { Pesticide species }}{\rightarrow} \mathrm{R}^{*}+\mathrm{H}_{2} \mathrm{O}
\end{gathered}
$$

Ion exchange was the best effective process in treating the target pesticides in this study. Removal efficiency of this process was highest with chlorpyrifos (83.2\%), fenobucarb (74.8\%), and diazinon (34.5\%), respectively. Adsorption of ion exchange resin for high molecular weight organic compounds could be the main mechanism which can effectively reduce the concentration of the target pesticides [21].

\section{Conclusion}

The removal of pollutants from wastewater of the target pesticide factory by the combination of the coagulation/flocculation, cold plasma and ion exchange process was demonstrated in this study. Application of the cold plasma combining with the coagulation/flocculation and ion exchange process was a promising alternative in removing pollutants from pesticide containing wastewater. Physicochemical parameters of wastewater treated via the system met the threshold value of the Viet Nam national technical regulation on industrial wastewater. The study also found that the removal efficiency of target pesticides was undesired as the expectation for the cold plasma process. Some challenges for the cold plasma application need to be further studied such as treatment time and increase of electrical conductivity.

\section{Acknowledgement}

This study is funded in part by the Can Tho University Improvement Project VN14 - P6, supported by a Japanese ODA loan. The authors would like to express sincere thanks to the enthusiastic support of the members during the project.

\section{Author Contributions}

T.V.P. (Associate Professor/Lecturer) was in the main role for collect- 
ing all information on the pesticide factory, wrote and revised the manuscript. V.M.P. (Master/Research Assistant) operated all the experiments and wrote the result section of the manuscript. D.V.N. (Ph.D/Lecturer) designed and guided for operating the cold plasma process of the models.

J.K. (Professor) checked and gave comments for revising the manuscript.

\section{References}

1. Toan PV, Sebesvari Z, Bläsing M, Rosendahl I, Renaud FG. Pesticide management and their residues in sediments and surface and drinking water in the Mekong Delta, Vietnam. Sci. Total Environ. 2013;452-453:28-39.

2. Nishimoto R. Global trends in the crop protection industry. J. Pestic. Sci. 2019;44:141-147.

3. OD Click. Situation and solution for pesticide production in Viet Nam [Internet]. OD click - People first for business [28 September 2018]. Available from: https://odclick.com/chuyen-san/phan-tich-nganh/thuc-trang-va-giai-phap-cho-nganh-t huoc-bao-ve-thuc-vat-tai-viet-nam/

4. Chavan M, Thacker NP, Tarar JL. Toxicity Evaluation of Pesticide Industry Wastewater through Fish Bioassay. IRA-Int. J.Appl. Sci. 2016;3:331-339.

5. Schramm JD, Hua I. Ultrasonic irradiation of dichlorvos: decomposition mechanism. Wat. Res. 2001;35:665-674.

6. Basfar AA, Mohamed KA, Al-Abduly AJ, Al-Kuraiji TS, Al-Shahrani AA. Degradation of diazinon contaminated waters by ionizing radiation. Radiat. Phys. Chem. 2007;76:1474-1479.

7. Ormad MP, Miguel N, Claver A, Matesanz JM, Ovelleiro JL. Pesticides removal in the process of drinking water production. Chemosphere 2008;71:97-106.

8. Alalm MG, Tawfik A, Ookawara S. Combined Solar advanced oxidation and PAC adsorption for removal of pesticides from industrial wastewater. J. Mater. Environ. Sci. 2015;6:800-809.

9. Bisht S, Nautiyal B, Bhatt UM, Joshi P. Plasma Applications for Environmental Protection. Int. J. Eng. Adv. Technol. (IJEAT). 2014;3:77-81.

10. Huang FM, Chen L, Wang HL, Feng TZ, Yan ZC. Degradation of methyl orange by atmospheric DBD plasma: Analysis of the degradation effects and degradation path. J. Electrost. 2012;70: 43-47.

11. Mouele ESM, Tijani JO, Fatoba OO, Petrik LF. Degradation of organic pollutants and microorganisms from wastewater using different dielectric barrier discharge configurations - a critical review. Environ. Sci. Pollut. Res. 2015;22:18345-18362.

12. Dung NV, 2015. Studies on applying cold plasma technology for water treatment: A literature review. Can. Tho. Univ. J. Sci. 2015;36:106-111.

13. Rong SP, Sun YB, Zhao ZH. Degradation of sulfadiazine antibiotics by water falling film dielectric barrier discharge. Chin. Chem. Lett. 2014;25:187-192.

14. Phong HQ, Dung NV, Hung NM, Huong HL, Giao DH. Study on decomposition of quinalphos pesticide under cold plasma system. Vietnamese J. Sci. Technol. 2018;184:3-9.

15. Bai Y, Chen J, Yang Y, Guo L, Zhang C. Degradation of organo- phosphorus pesticide induces by oxygen plasma: Effects of operating parameters and reaction mechanisms. Chemosphere 2010;81:408-414.

16. Dung NV, Phong HQ, Toan PV, Tuyen NV, Lavane K. Treatment of surface water using cold plasma for domestic water supply. Environ. Eng. Res. 2019;24:412-417.

17. Kuraica MM, Obradović BM, Manojlović D, Ostojić DR, Purić J. Application of coaxial dielectric barrier discharge for potable and waste water treatment. J. Ind. Eng. Chem. Res. 2006;45: 882-905.

18. Tanakaran Y and Matra K. Wastewater treatment by dielectric barrier discharge plasma. Journal of Physics: Conference Series, In: International Nuclear Science and Technology Conference; 4-6 February 2019; Centara Grand at Central Ladprao, Bangkok, Thailand. 1285:012015.

19. Marañón E, Castrillón L, Fernández NY, Fernández MA. Colour, turbidity and COD removal from old landfill leachate by coagulation-flocculation treatment. Waste Manag Res. 2010;28:731-737.

20. Pariatamby A, Kee YL. Persistent organic pollutants management and remediation. Procedia Environ. Sci. 2016;31:842-848.

21. Misra R, Satyanarayan S, Potle N. Treatment of agrochemical/ pesticide wastewater by coagulation/flocculation process. Int. J. Chem. Physical Sci. IJCPS. 2013;Special Issue:39-51.

22. Clifford DA. Chapter 9: Ion exchange and inorganic adsorption. In: Water quality \& treatment - A handbook of community water supplies. Fifth Ed., American Water Works Association; 1999:1-35.

23. Humbertb H, Gallarda H, Sutyb H, Croue JP. Natural organic matter (NOM) and pesticides removal using a combination of ion exchange resin and powdered activated carbon (PAC). Wat. Res. 2008;42:1635-1643.

24. Boyer TH. Removal of Dissolved Organic Matter by Magnetic Ion Exchange Resin. Curr. Pollut. Rep. 2015;1:142-154.

25. Senevirathna STMLD, Tanaka S, Fujii S, et al. A comparative study of adsorption of perfluorooctane sulfonate (PFOS) onto granular activated carbon, ion-exchange polymers and non-ion-exchange polymers. Chemosphere 2010;80:647-651.

26. Wu J, Lan C, Chan GYS. Organophosphorus pesticide ozonation and formation of oxon intermediates. Chemosphere 2009;76: 1308-1314.

27. APHA. APHA standard methods for the examination of water and wastewater. Washington D.C; 2012.

28. BTNMT, the Ministry of Natural Resources and Environment, Viet Nam. National technical regulation on industrial wastewater (QCVN 40:2011/BTNMT) [cited on 11 April 2020]. Available from:http://vukhcn.monre.gov.vn/tieu-chuan-quy-chuan/ quy-chuan-vn?page $=2 \&$ ten $=\&$ linhvuc $=0$

29. WHO, World Health Organization. The WHO recommended classification of pesticides by hazard and guidelines to classification 2009. Geneva: International Program on Chemical Safety (IPCS) \& World Health Organization [2010]. Available from: http://www.who.int/ipcs/publications/pesticides_hazard_2009.pdf

30. Nobonita D, Suchismita D. Chlorpyrifos Toxicity in Fish: A Review. Curr. World Environ. 2013;8:77-84.

31. Cong NV, Phuong NT. Critical review effects of insecticide diazinon on snakehead fish (Channa striata). Can. Tho. Univ. 
J. Sci. 2011;17a:133-140.

32. Tomlin CDS. The Pesticide Manual: A World Compendium, 14th ed. British Crop Protection Council: Hampshire, UK; 2006.

33. Báez ME, Espinoza J, Fuentes E. Degradation kinetics of chlorpyrifos and diazinon in volcanic and non-volcanic soils: influence of cyclodextrins. Environ. Sci. Pollut. Res. 2018;25:2502025035.

34. Deer HM. Effect of water $\mathrm{pH}$ on the chemical stability of pesticide [Fact sheet]. Utah State University; 2001.

35. Linh TT, Cong NV. Effects of insecticide diazinon on activity of enzyme cholinesterase in Climbing perch (Anabas testudineus): Effects of temperature and dissolved oxygen. Can. Tho. Univ. J. Sci. 2009;11:33-40.

36. Giddings JM, Williams WM, Solomon KR, Giesy JP. Risks to Aquatic Organisms from Use of Chlorpyrifos in the United States. In: Giesy J., Solomon K. (Eds) Ecological Risk Assessment for Chlorpyrifos in Terrestrial and Aquatic Systems in the United States. Reviews of Environmental Contamination and Toxicology (Continuation of Residue Reviews). Springer, Cham. 2014.119-162.

37. Stadlinger N, Berg H, Brink PJVD, Tam NT, Gunnarsson JS.
Comparison of predicted aquatic risks of pesticides used under different rice-farming strategies in the Mekong Delta, Vietnam. Environ. Sci. Pollut. Res. 2018;25:13322-13334.

38. Jiang B, Zheng J, Qiu S, Wu M, Zhang Q, Yan Z, Xue Q. Review on electrical discharge plasma technology for wastewater remediation. Chem. Eng. J. 2014;236:348-368.

39. Autin O, Hart J, Jarvis P, Adam JM, Parsons SA, Jefferson B. The impact of background organic matter and alkalinity on the degradation of the pesticide metaldehyde by two advanced oxidation processes: $\mathrm{UV} / \mathrm{H}_{2} \mathrm{O}_{2}$ and $\mathrm{UV} / \mathrm{TiO}$. Water Res. 2013;47: 2041-2049.

40. Levchuk I, Marquez JJR, Sillanpaa M. Removal of natural organic matter (NOM) from water by ion exchange-A review. Chemosphere 2018;192:90-104.

41. Hijosa VM, Molina R, Montras A, Muller M, Bayona JM. Decontamination of waterborne chemical pollutants by using atmospheric pressure non-thermal plasma: a review. Environ. Technol. Rev. 2014;3:71-91.

42. Hattab MTA, Ghaly AE. Disposal and Treatment Methods for Pesticide Containing Wastewaters: Critical Review and Comparative Analysis. J. Environ. Prot. 2012;3:431-453. 